Abstracta Iranica Abstracta Iranica

Revue bibliographique pour le domaine irano-aryen

Volume 34-35-36 | 2017

Comptes rendus des publications de 2011-2013

\title{
Werner Sundermann (avec la collaboration de Desmond Durkin-Meisterernst). Die Rede der lebendigen Seele. Ein manichäischer Hymnenzyklus in mittelpersischer und sogdischer Sprache
}

Agnes Korn

\section{OpenEdition}

Journals

Édition électronique

URL : http://journals.openedition.org/abstractairanica/42022

DOI : $10.4000 /$ abstractairanica.42022

ISSN : 1961-960X

Éditeur :

CNRS (UMR 7528 Mondes iraniens et indiens), Éditions de l'IFRI

Référence électronique

Agnes Korn, «Werner Sundermann (avec la collaboration de Desmond Durkin-Meisterernst). Die Rede der lebendigen Seele. Ein manichäischer Hymnenzyklus in mittelpersischer und sogdischer Sprache », Abstracta Iranica [En ligne], Volume 34-35-36 | 2017, document 7, mis en ligne le 30 juillet 2017, consulté le 26 septembre 2020. URL : http://journals.openedition.org/abstractairanica/42022 ; DOI : https://doi.org/10.4000/abstractairanica.42022

Ce document a été généré automatiquement le 26 septembre 2020.

Tous droits réservés 


\title{
Werner Sundermann (avec la
} collaboration de Desmond DurkinMeisterernst). Die Rede der lebendigen Seele. Ein manichäischer Hymnenzyklus in mittelpersischer und sogdischer Sprache

\author{
Agnes Korn
}

\section{RÉFÉRENCE}

Werner Sundermann (avec la collaboration de Desmond Durkin-Meisterernst). Die Rede der lebendigen Seele. Ein manichäischer Hymnenzyklus in mittelpersischer und sogdischer Sprache. Turnhout, Brepols, 2012, 230 p. +5 planches (Berliner Turfantexte, XXX)

1 Cette édition présente les fragments manichéens identifiés comme appartenant à un cycle d'hymnes dits "de l'âme vivante " (moyen-perse grīw zindag). Cette entité centrale du manichéisme, l'âme du monde, représente la totalité des âmes humaines, qui se trouvent d'abord dans leurs corps et, après leur mort, dans les plantes, les animaux et les étoiles; en même temps, l'âme vivante correspond à la lumière que la Création a emprisonnée dans le monde. La vénération qui lui est rendue par les manichéens est par conséquent une composante essentielle de cette religion, visant à sauver le monde, d'où l'importance de ce type d'hymnes. Il s'agit de textes en vers (chacun écrit sur deux lignes dans les manuscrits) que l'éditeur a regroupés en vingt parties, formant 250 vers au total.

2 Bien que l'appartenance des fragments individuels ainsi que leur ordre dans ce cycle d'hymnes ne soient pas tout à fait sûrs, l'A. présente ici le résultat de son travail de re- 
composition du texte, le volume suivant le plan général d'édition des fragments de l'Académie des Sciences de Berlin. Après une introduction abordant le cycle des hymnes à l'âme vivante et une description des 54 fragments (dont sept en sogdien et les autres en moyen-perse) que l'éditeur attribue à ce cycle (p. 7-50), la partie centrale du volume (p. 98-159) présente le texte que l'éditeur a constitué à partir des fragments, arrangé dans l'ordre qu'il propose, avec une traduction en allemand (une traduction en anglais est également donnée, p. 177-196) suivie par des notes (p. 160-176).

3 Cet ensemble est précédé (p. 51-97) par la translittération des fragments ordonnée par ligne, agencée de façon à ce que les doublons (donnant le même texte) soient classés ensemble. À la fin du volume sont données la liste des mots figurant dans le texte, la bibliographie ainsi que cinq planches de photos de quelques fragments (parmi lesquels un récemment trouvé).

4 Le présent volume témoigne de l'excellence de l'expertise du feu auteur à la fois sur la religion manichéenne, la codicologie et paléographie de ces fragments (dont quelquesuns sont assez petits), et constitue une œuvre supplémentaire à mettre au compte de ses travaux sur la collection des manuscrits manichéens.

\section{AUTEURS}

\section{AGNES KORN}

CNRS, Mondes iranien et indien 